\title{
Undefined Organic Additives Stimulates in Vitro Seed Germination of Dendrobium Ovatum (Willd.) Kraenzl, a Medicinal Orchid
}

\author{
Thejaswini $\mathrm{R}$ and Narasimhan $\mathrm{S}$ \\ Department of Biotechnology, Manipal Institute of Technology, Manipal University, Manipal, India \\ Email: tejaswinisriram@gmail.com, narasimhan.s@manipal.edu
}

\begin{abstract}
Dendrobium ovatum (Willd.) Kraenzl is an epiphytic orchid belonging to the family Orchidaceae. The aim of the current study is to analyze the efficacy of undefined additives such as coconut water, palm fruit water (Borassus flabellifer), tomato juice and pineapple juice on the germination and growth of in vitro cultured seeds of $D$. ovatum. The germination was analyzed using scanning electron microscopy (SEM). Among all the additives $30 \%$ coconut water ( $v / v)$ induced maximum rate of embryo germination . Tomato juice and pineapple juice $(15 \% \mathrm{v} / \mathrm{v})$ also exhibited better germination rate of orchid seeds under in vitro conditions. Protocorm like bodies were seen growing and further develops into young plant. SEM served as an early analytical tool for the response of seeds and revealed heterogeneity of seeds in terms of its response towards germination.
\end{abstract}

Index Terms - coconut water, in vitro germination, undefined additives

\section{INTRODUCTION}

The response of plants during in vitro culture can be significantly altered using varying regime of plant growth regulators, sucrose sources and cultural conditions. This has been studied in detail by many authors [1], [2]. An alternate strategy is to use the additives such as fruit juices, fruit water and other organic supplements [3]. Being undefined, the constituents of these additives are unknown and hence a less data is available regarding its use in plant cell and tissue cultures. Such organic additives used in tissue culture remains chemically undefined regarding its constituents and also contains some growth hormones [4]. We have investigated the four commonly available additives belonging to two classes such as fruit water (Embryo sac water such as Coconut water and palmyra palm fruit water) and fruit juices (tomato juice and pineapple juice). We have selected seeds of an orchid as the model system, because orchid seeds are non-endospermic and only contains the embryo. Hence we believe that the germination of these seeds can be best affected alone by the constituents of the media provided in the tissue culture.

Manuscript Received October 9, 2016; revised January 23, 2017.

\section{MATERIALS AND METHODS}

Dendrobium ovatum seeds were collected from the mature capsules just before its dispersal during the month of January, 2016 growing in the campus of Manipal University, Manipal. The pods were washed with running tap water for 20 minutes and chemically sterilized with $0.1 \%$ mercuric chloride (w/v) for eight minutes. After chemical sterilization the seeds were inoculated in Woody Plant Medium [5] containing 0.5 $\mathrm{mg} / \mathrm{l}$ Napthalene acetic acid (NAA) and $1 \mathrm{mg} / \mathrm{l}$ Benzyl Adenine (BA) with varying concentrations of the additives. The concentration of additives selected for the study were $1 \%, 10 \%, 15 \%, 20 \%$ and $30 \%(\mathrm{v} / \mathrm{v})$. Coconut water was collected from young tender coconuts. For palm water, mature palm fruits were used. The juice from pine apple and tomato were prepared by crushing the fruits using an electrical grinder and filtered with Whatsman No. 1 filter paper. The medium was gelled with $0.8 \%$ (w/v) agar. The cultures were incubated under a photoperiod of 12 hours with a luminous intensity of 900 lux at a temperature of $25^{\circ} \mathrm{C}$. Media without additives served as the control sample. Studies were carried out in five replications. SEM analysis was done by using a Carl Zeiss EVO 18 Special Edition SEM.

\section{RESUlTS AND DISCUSSION}

The seeds started germination within two weeks of incubation. The cultures showed direct germination though protocorm like body formation. The responses of the cultured seeds in presence of various additives tested are summarized in the Table I. In the absence of organic additives there was no visible symptoms of germination response with in 21 days.

Maximum rate of embryo germination was obtained with $30 \%$ of coconut water as an additive with in 30 days of incubation (Fig. 1). While maximum inhibitory response was obtained with $30 \%$ of pineapple juice, eventhough lower concentrations were effective in inducing the germination. In the case of pineapple juice, maximum rate of in vitro germination was obtained with a concentration of $15 \%$ (Table I). Among the additives studies, coconut water proved to be the best for in vitro germination and growth of $D$. ovatum seeds. 
TABLE I. EFFECT OF UNDEFINED ADDITIVES ON THE IN VITRO GERMIANTION OF SEEDS OF $D$. OVATUM

\begin{tabular}{|l|c|c|c|c|c|}
\hline $\begin{array}{l}\text { Name of } \\
\text { additive }\end{array}$ & $\mathbf{1 \%}$ & $\mathbf{1 0 \%}$ & $\mathbf{1 5 \%}$ & $\mathbf{2 0 \%}$ & $\mathbf{3 0 \%}$ \\
\hline $\begin{array}{l}\text { Coconut } \\
\text { water }\end{array}$ & ++ & +++ & +++ & ++ & ++++ \\
\hline $\begin{array}{l}\text { Palm fruit } \\
\text { water }\end{array}$ & + & +++ & ++ & ++ & ++ \\
\hline $\begin{array}{l}\text { Tomato } \\
\text { juice }\end{array}$ & ++ & ++ & +++ & ++ & + \\
\hline $\begin{array}{l}\text { Pineapple } \\
\text { juice }\end{array}$ & ++ & +++ & +++ & ++ & + \\
\hline
\end{tabular}

,,,++++++++++ indicates increasing order of germination

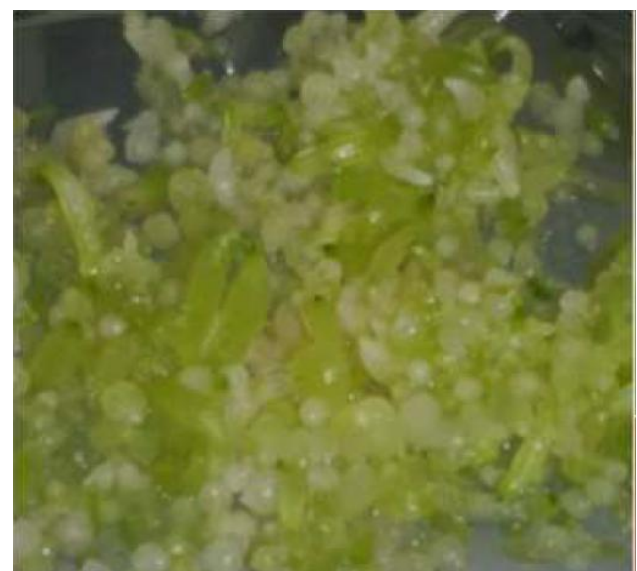

Figure 1. In vitro germination of seeds in presence of $30 \%(\mathrm{v} / \mathrm{v})$ coconut water after 30 days of incubation

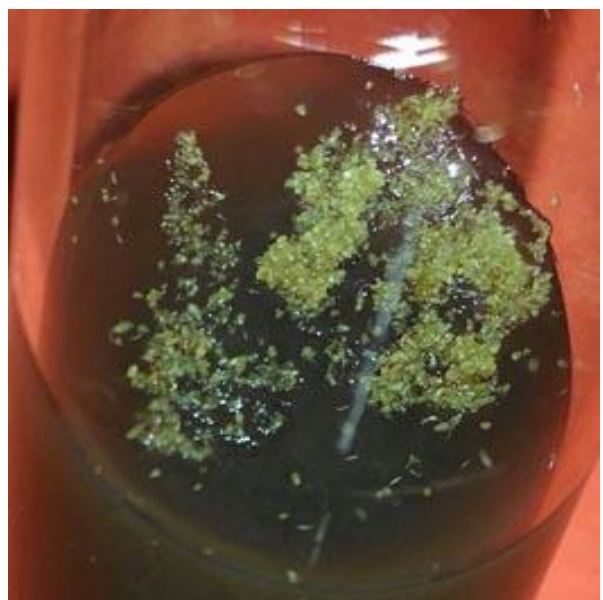

Figure 2. Response of in vitro germination in presence of $10 \%(\mathrm{v} / \mathrm{v})$ palm fruit water. The medium changed black due to phenolic content oxidation of the additive.

SEM analyses showed that the germination started as a small protuberance measuring around $10 \mu$ from the seed, fruther as a protocorm like body and later it elongated to produce a visible green color small plantlet. Hence SEM analysis served as an ideal tool for early detection of in vitro seed response (Fig. 3). SEM analysis also revealed there is a heterogeneity among the seeds regarding the response. Some seeds responded fast and exhibited early germination and fast growth rate, while others responded slowly (Fig. 3, 4). Some of the seeds do not germinate at all. A single orchid capsule contains microscopic millions of seeds [11], but not all seeds are germinated under in vitro conditons. This further justifies why the plant is producing such an enormous number of seeds.

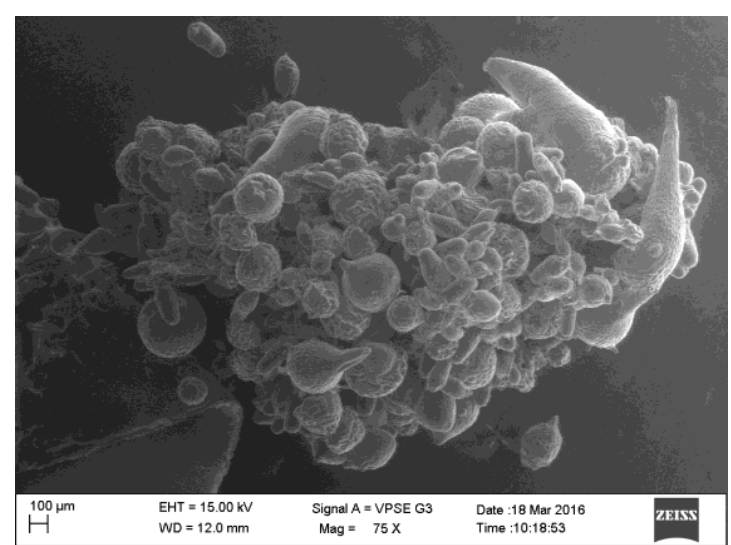

Figure 3. SEM analysis of germination after 21 days of incubation Note the heterogenity in the response of microscopic seeds, some seeds responds fast, while others medium response and some fails to germinate.

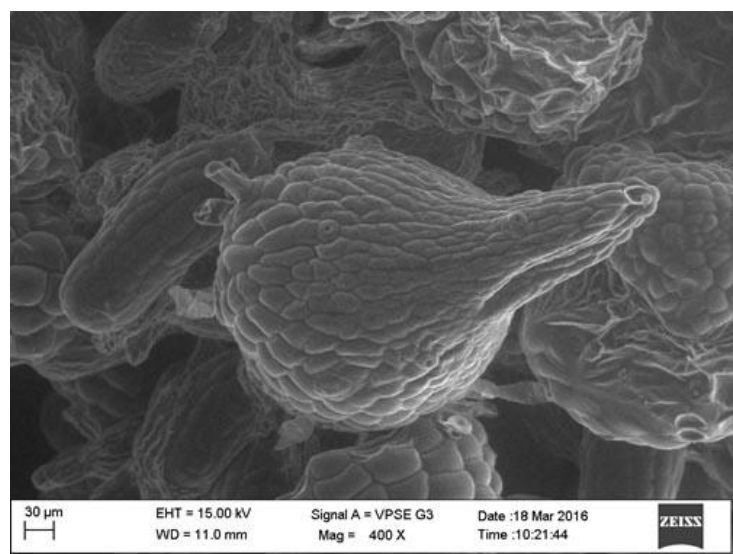

Figure 4. Enlarged view showing the initial stages of germination of an orchid seed.

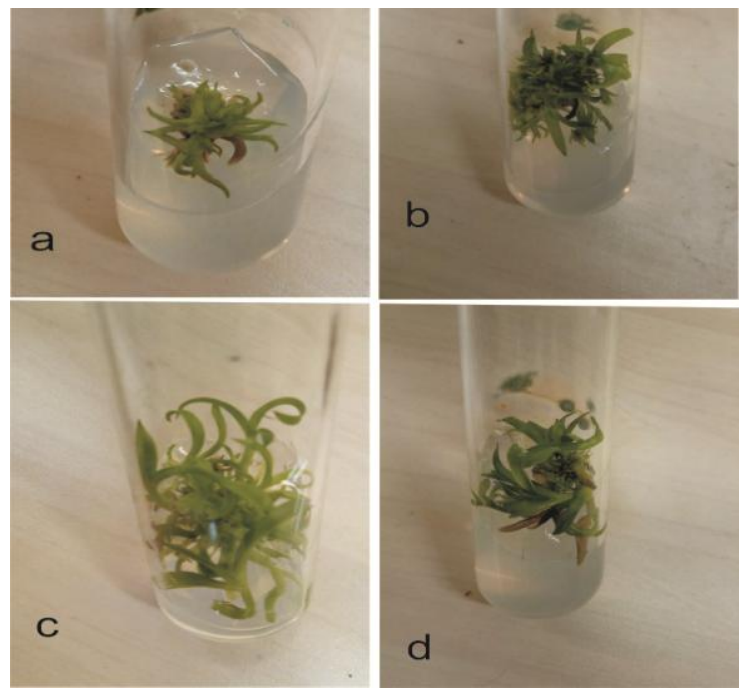

Figure 5. Shoot induction of D. ovatum 
Further axillary shoot multiplication was noted when microshoots were further subcultured in MS media containing $0.5 \mathrm{mg} / \mathrm{l} \mathrm{NAA}$ and $1 \mathrm{mg} / \mathrm{l} \mathrm{BA}$. A maximum of 20 buds were developed [Fig. 5] and they have elongated well [Fig. 5] enabling hardening and transplantation. Similar results were also obtained in Cymbidum ensifolium regarding induction of upright shoots [12].

The use of undefined organic additives for the in vitro growth and propagation is also experimented in other orchids such as Phalaenopsis violacea [13], hybrids of Dendrobium [14] and Vanda [15].

\section{CONCLUSIONS}

Current study prooved that the seeds of the D. ovatum germinates well in presence of organic additives. It also supports the possibility of using organic additives as a substitute for plant growth regulat ors. Further, the response of orchid seeds can be easily accessed by the scanning electron microscopy.

\section{ACKNOWLEDGMENT}

The authors acknowledges the Head of the Department of Biotechnology, Manipal Institute of Technology for the facilities provided

\section{REFERENCES}

[1] G. R. Rout, A. Mohaptra, and S. M. Jain, "Tssue culture of ornamental pot plant: A critical review on present scenario and future prospects," Biotechnology Advances, vol. 24, pp. 531-560, 2006.

[2] M. Yaseen, T. Ahmad, G. Sablok, A. Standardi, and I. H. Hafiz, "Review: Role of carbon sources for in vitro plant growth and development," Molecular Biology Reports, vol. 40, pp. 2837-2849, April 2013.

[3] T. A. Thorpe, C. Stasolla, E. C. Yeung, G. J. de Klerk, A. Robers, and E. F. George, "The components of plant tissue culture media II: Organic additions, osmotic and PH effects and support systems," in Plant Propagation by Tissue Culture, E. F. George, M. A. Hall, and G. J. de Klerk, Eds., Dordrecht: Springer-Verlag, 2008, pp. 115-173.

[4] I. Manawadu, N. Dahanayake, and S. G. N. Senanayake, "Effectsof different natural organic additives on in vitro shot regenration of Raphanus sativus L. var. Beeralu," Journal of Agricultural Science and Technology, vol. A4, pp. 219-223, March 2014.

[5] G. Lloyd and B. McCown, "Commercially feasible micropropagation of mountain laurel, Kalmia latifolia, by use of shoot-tip culture," Combined Proceedings of International Plant Propagators Society, vol. 30, pp. 421-427, 1980.

[6] J. Arditti, Micropropagation of Orchids, 2nd ed., USA: WilyBlackwell, 2009, p. 6.

[7] M. A. Sandoval Prando, P. Chiavazza, A. Faggio, and C. Contessa "Effect of coconut water and growth regulator supplements on in vitro propagation of Corylus avellana L," Scientia Horticulture, vol. 171, pp. 91-94, May 2014.
[8] A. Peixe, A. Raposo, R. Lourenço, H. Cardoso, and E. Macedo, "Coconut water and BAP successfully replaced zeatin in olive (Olea europaea L.) micropropagation," Scinetia Horticulture, vol. 113, pp. 1-7, June 2007.

[9] M. S. Sudarshana, M. H. Niranjan, and N. Rajashekar, "Borassus pulp as substitute for sucrose and vitamins for in vitro cultures of some indian medicinal plants," International Journal of Pharma and Bio Sciences, vol. 3, pp. B414-420, Jan. 2012

[10] S. Kaur and K. K. Bhutani, "Organic growth supplement stimulants for in vitro multiplication of Cymbidium pendulum (Roxb.) Sw.," Horticulture Science (Prague), vol. 39, pp. 47-52, 2012.

[11] S. Paul, S. Kumaria, and P. Tandon. (December 2011). An effective nutrient medium for asymbiotic seed germination and large-scale in vitro regeneration of Dendrobium hookerianum, a threatened orchid of northeast India. AoB Plants. [Online]. Available: https://doi.org/10.1093/aobpla/plr032

[12] J. Arditti, Micropropagation of ORchids, 2nd ed., USA: Blackwell , 2009, p. 461

[13] P. Gnasekaran, X. Rathinam, U. R. Sinniah, and S. Subramaniam, "A study on the use of organic additives on the protocorm-like bodies (PLBS) growth of Phalaenopsis violacea orchid," Journal of Phytology, vol. 2, no. 1, pp. 29-33, 2010.

[14] N. Nambiar, C. S. Tee, and M. Maziah, "Effects of organic additives and different carbohydrate sources on proliferation of protocormlike bodies in Dendrobium Alya Pink," Plant Omics Journal, vol. 5, no. 1, pp. 10-18, 2012.

[15] P. Gnasekaran, R. Poobathy, M. Mahmood, M. R. Saiman, and S. Subramaniam, "Effect of complex organic additives on improving the growth of PLBS of Vanda Kasem's Delight," Australian Journal of Crop Sciences, vol. 6, no. 8, pp. 1245-1248, 2012.

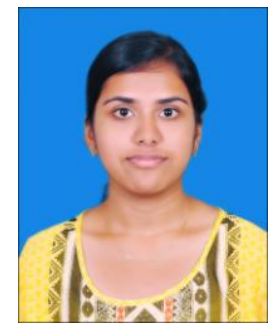

Thejaswini R, student at Manipal Institute of Technology (MIT), Manipal University, is currently pursuing $M$ Tech in Industrial Biotechnology, Manipal, India, Pursued BTech (2012 -2016) in Biotechnology from MIT, did schooling from Rukmani Vidyalaya, Chennai. Born in Karnataka, and brought up in different parts of India - Bangalore, Delhi, Hyderabad and Chennai. Can speak five different languages fluently -English, Hindi, Kannada, Tamil and Telugu. Have got wide variety of interests, especially in exploring new things, hobbies include reading books, painting and social work. She has also completed all three levels in National Cadet Corp. She believes that Scientific Research should be as sound and complete as possible using interdisciplinary expertise. Research interests: Plant biotechnology, Nanobiotechnology and Bioinformatics. She has completed her Internship from Biological E Limited, Hyderabad, India

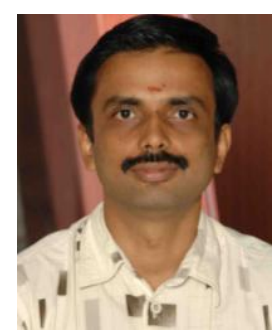

Narasimhan S received his PhD in 2005 from University of Kerala. His research work includes conservation biology and in vitro approaches of plant cell and tissue culture. He currently teaches plant biotechnology for engineering students. His research group includes three doctoral students in the area of biodiversity, light induced secondary metabolites in medicinal plants and bioprospecting of lichens 